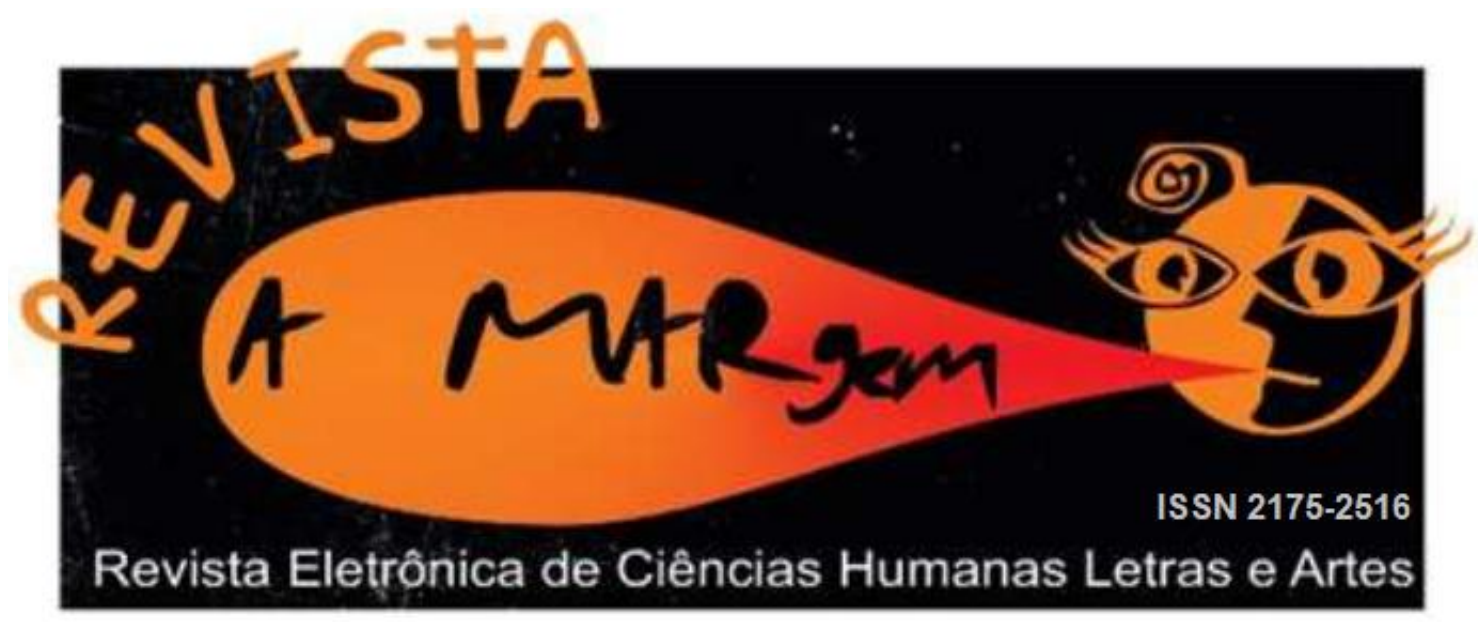

\title{
DINA SALÚSTIO E AS DIFERENTES FORMAS DE REPRESENTAÇÃO DA MULHER NA LITERATURA CABO-VERDIANA ${ }^{1}$
}

\author{
Ana Carine de Sousa \\ Universidade Estadual do Piauí (UESPI) \\ Andressa Costa da Conceição \\ Universidade Estadual do Piauí (UESPI) \\ Francisca de Paula Sousa Araújo \\ Universidade Estadual do Piauí (UESPI)
}

\begin{abstract}
Resumo: O presente artigo baseou-se na obra Mornas eram as Noites (1994), da escritora caboverdiana Dina Salústio e tem por objetivo problematizar diferentes formas de representação da mulher, além de desenvolver uma reflexão a condição feminina, a qual o livro tanto aborda. A autora, por meio de diferentes figuras femininas, analisa e discute o contexto social onde essas mulheres estão inseridas, em que o preconceito, a desigualdade de gênero e a idealização da mulher, são fatores que ainda persistem. Fatos evidenciados por Salústio talvez também por esta ser, além de escritora, assistente social e jornalista. Além de evidenciar a continuidade de uma sociedade que ainda se mantém com o pensamento e comportamento patriarcal. Nesse sentido, a temática a ser abordada retrata o modo como muitas mulheres cabo-verdianas vivem na realidade. Buscou-se deixar claro a interpretação das ideias da autora tendo como suportes teóricos para a confecção deste artigo nomes como Salústio (2002), Laranjeira (1992), Tedeschi (2019), dentre outros.
\end{abstract}

Palavras-chave: Desigualdade de gênero; Mulher; Condição feminina.

Dina Salústio and the differents ways of representation of woman in Cape-Verdean literature

Abstract: This article was based on the work Mornas eram as Noites (1994), by Cape-Verdean writer Dina Salústio and aims to problematize different forms of representation of woman, in addition to developing a reflection on the female condition, which the book addresses so much. The author, through different female figures, analyzes and discusses the social context where these women are inserted, in which prejudice, gender inequality and the idealization of women, are factors that still persist. Facts evidenced by Salústio perhaps also by this being, in addition to being a writer, social worker and journalist. In addition to showing the continuity of a society that still maintains patriarchal thinking and behavior. In this sense, the theme to be addressed

\footnotetext{
${ }^{1}$ Artigo científico apresentado para obtenção da nota na disciplina de Literaturas Africanas de Língua Portuguesa ministrada pela professora Iramí Soares Mineiro do Curso de Letras-Português da UESPI e submetido à III Jornada de Literatura e Africanidades em dezembro de 2019.
} 
portrays the way in which many Cape-Verdean women live in reality. It was sought to make clear the interpretation of the author's ideas, having as theoretical support for the making of this article names such as Salústio (2002), Laranjeira (1992), Tedeschi (2019), among others.

Keywords: Gender inequality; Woman; Female condition.

\section{Introdução}

A pesquisadora Dina Salústio busca destacar os estigmas deixados pelas diferentes formas de representação da mulher no seu âmbito social. É importante frisar a relevância que Cabo Verde tem na construção de vivências e sentimentos (LARANJEIRA, 1992) na literatura feminina, que ecoam pelos vários espaços do arquipélago cabo-verdiano.

O continente africano é o terceiro maior do mundo, contém mais de um bilhão de pessoas, com diversos problemas sociais, como a miséria, baixa qualidade de vida e muita violência (CABO, 2018; PENA, 2012), violência essa que parece estar mais voltada para a mulher, como é problematizado na obra de Salústio. No continente são faladas mais de mil línguas, entre elas o crioulo, língua-mãe de Cabo Verde - no entanto, o português é a língua oficial. Cabo Verde é composto geograficamente de dez ilhas, das quais Santiago é a "Ilha mãe" por concentrar maior quantidade de habitantes. É um arquipélago perpassado por vulcões, secas, pobre em recursos naturais e com pouca terra (CÔRTES; SANTOS; SANTOS, 2018; CABO, 2018). Em face de seus desatinos, o arquipélago encontra na literatura brasileira uma relação de intertextualidade, principalmente com autores do Nordeste que retratam a seca, a fome como Graciliano Ramos, Jorge Amado, pela influência do solo no caráter e nos costumes dos seus habitantes. E também com Rachel de Queiroz que defende a participação das mulheres na vida pública e escreve sobre a resiliência nata das formas femininas nordestinas frente às adversidades, a exemplo do romance modernista "O Quinze", publicado em 1930, que trata da história de vida da personagem Conceição, explorada por Laile de Abreu em entrevista à Mayara Paixão para o site Brasil de Fato em 2017:

Conceição que é uma mulher atípica, em sua época, é uma construção absolutamente livre e independente, impensada para uma mulher da década de 1930, que é o momento em que a obra foi publicada. Era uma mulher que viveu, no tempo cronológico da obra, em 1915, mas que não pensava em ter filhos, que trabalhava fora e conquistou um espaço do lar, de casa, mas também conquistou um espaço externo. E eram questões impensadas para a mulher (PAIXÃO, 2017).

Raquel de Queiroz influenciou em grande parte a vida da escritora Dina Salústio, desde sua infância, a qual defende a representação da mulher feita através da recuperação de gestos, ritmos e sensibilidades silenciadas ao longo da história, articulado em sua cultura. 
De acordo com Laranjeira (1992, p. 43) “o movimento cultural - sobretudo literário - da revista Claridade, surgido em Cabo Verde, em 1936, renovou profundamente a literatura do arquipélago". Ainda segundo Laranjeira (1992) o romance Chiquinho, do cabo-verdiano Baltasar Lopes, foi publicado logo na primeira edição da revista e, embora o romance não tivesse em certo sentindo preocupações sociais, ainda hoje é considerado uma bíblia romanesca em Cabo Verde. Além disso, o autor citado acima afirma que "a crítica literária cabo-verdeana dos anos 60, de feição militante, portanto com uma fundamentação radical, apodou a literatura clarista (inclusive Chiquinho) de evasionista, quer dizer, de tendência para a evasão, a fuga, desvinculada do real social, político e económico" (LARANJEIRA, 1992, p. 44).

Nota-se que o período da revista abriu espaço para a reinvenção da escrita na produção literária cabo-verdiana, em um ponto de vista realista, enquadrado no concreto social. No entanto, o tempo de "denúncia" ainda estava por vir, tal como Salústio bem expõe nos seus contos e prosas no que tange à mulher. Com isso, ela "[...] traz à tona a violência comum na vida da mulher, ser que sofre com maior peso a subjugação diante das subalternidades africanas no contexto da exploração" (CÔRTES; SANTOS; SANTOS, 2018, p. 52).

Levando em conta que Dina Salústio reflete e traz uma discussão sobre a situação de violência sofrida pela mulher, compreende-se que a autora busca mostrar em suas obras os impactos negativos do drama feminino na literatura cabo-verdiana pontuando o preconceito e a desigualdade social como aspectos nítidos de problemáticas sociais vivenciados pela população feminina do arquipélago. Por conseguinte, a escrita da autora faz um levantamento sobre o poder feminino na produção textual africana, que alça voos depois da Independência de Cabo Verde em 1975, torna-se uma literatura de resistência, de força, ora incumbida pelo silenciamento ou pela vociferação:

\footnotetext{
escrever a história das mulheres? Durante muito tempo foi uma questão incongruente ou ausente. Voltadas ao silêncio da produção materna e doméstica, na sombra da domesticidade que não merece ser quantificada nem narrada, terão mesmo as mulheres uma história? (DUBY; PERROT, 1990, p. 07 apud TEDESCHI, 2016, p. 153).
}

Desse modo, a mulher não era vista como uma intelectual capaz de produzir obras literárias e muito menos terem suas histórias de vida contadas (a não ser que fosse algo que remetesse ao ambiente doméstico), uma vez que em grande parte da sociedade, por muito tempo, escrever foi um papel voltado somente para o homem. Todavia, escrever resultou-se para mulher um ato de rebeldia, uma ferramenta de protesto e de engajamento por uma luta 
social que pretendia alcançar os direitos do público feminino, mesmo diante de diversos desafios pela conquista do seu espaço e da sua liberdade de expressão.

Ademais, é importante destacar algumas curiosidades sobre a renomada escritora e prosadora cabo-verdiana Bernardina Oliveira de Salústio, sob o pseudônimo de Dina Salústio que nasceu em 1941, na ilha de Santo Antão, Cabo Verde. Atualmente, a pesquisadora exerce a função de escritora, assistente social e jornalista. Além de ter sido diretora de um programa de rádio e colaboradora das revistas Mujer e Ponto \& Vírgula (de intercâmbio cultural com vários autores como Baltasar Lopes, Antônio Carreira, Germano Almeida, entre outros), foi membro técnica do Ministério dos Negócios Estrangeiros de Cabo Verde. Salústio produziu várias obras como A Louca de Serrano (1998), Filhas do Vento (1999), e a obra desse artigo, Mornas eram as Noites. Esse último é livro de crônicas e minicontos produzido em 1994. A escritora traz em suas obras características pertinentes ao contexto cabo-verdiano e quiçá universal, bem como a questão relacionada à mulher e sua representação literária e social. Na problemática da representação, é vista por Tedeschi, na análise à conduta da escrita feminina como uma "inovação libertária":

As mulheres escritoras representam as correntes mais vivas e mais críticas do pensamento feminino. A libertação das mulheres, representada na escrita literária, defende a necessidade de uma nova referência do seu próprio ser, como construção de sua identidade social edificada por oposição a toda definição imposta, ao longo dos tempos (TEDESCHI, 2016, p. 163).

Dessa forma, é possível perceber que Dina Salústio faz uso da escrita como meio revelador social da discriminação, a qual as mulheres africanas e, principalmente, caboverdianas fazem parte. Para a autora escrever sobre as mulheres cabo-verdianas é uma tentativa de mostrar, por meio da Literatura, como a sua cultura ainda as subjuga, colocando-as em condições submissas em diversos aspectos de seus cotidianos.

Talvez seja esse o motivo para um número considerável de suas obras trazerem tão nitidamente questões sobre violência doméstica, agressões físicas, verbais e psicológicas a mulheres em muitos ambientes, sejam eles familiares, de trabalho, religiosos e entre outros.

Em Mornas eram as Noites a autora cita esses temas em forma de contos. Além desta obra, ela escreveu romances e ensaios na mesma temática, tais como os romances A Louca de Serrano e Filhas do Vento e o ensaio intitulado Violência Contra as Mulheres (1999), escreveu também para o público infanto-juvenil. Salústio é contemporânea e notória, sendo "[...] uma das ficcionistas mais conhecidas da literatura cabo-verdiana, que, através da poesia e do ensaio, vem despertando no leitor o interesse de conhecer melhor a jovem literatura cabo-verdiana" 
(BRITO; LIMA, 2015, p. 56-57). Esse despertar, por meio da leitura salustiana, pode ser pelo fato de a escritora ter foco nas necessidades socioculturais de seu país e querer pontuá-las num momento pertinente da literatura de Cabo Verde, embora ficcionais, suas histórias dizem muito sobre o viver de seu povo.

Braga (2014) aponta que em A Louca de Serrano tem-se o primeiro romance caboverdiano escrito por uma mulher; tendo nessa história ficcional os relatos dos habitantes da aldeia Serrano, também fictícia, sobre os acontecimentos diários que enfrentam entres os espaços rural e urbano, as questões culturais e os discursos travados por esses personagens. Com esse romance, Salústio alcança "a promoção de importantes rupturas na atual fíç̧ão islenha, marcando assim, de forma assaz singular, a literatura cabo-verdiana contemporânea" (ALMADA, 2007, p. 1 apud BRAGA, 2014, p. 91).

A Louca de Serrano traz ainda a ideia de uma associação entre conhecimento e liberdade, vivenciados pela personagem Filipa: "O seu encontro com a palavra se faz pela descoberta da liberdade" (BRAGA, 2014, p. 96). Com isso, entende-se que Salústio interliga esses dois aspectos conhecimento/liberdade como um em consequência do outro.

\section{Mornas eram as Noites: um livro, várias histórias}

Percebe-se que a literatura salustiana pode ser impactante ao leitor, tendo em vista que a autora parece pensar cautelosamente no que vai escrever. Não à toa, o vocábulo morna segundo Brito e Lima (2015, p. 56) “[...] está associado a diferentes significados [...] é também uma modalidade poética em que os povos insulares expressam a alegria, a dor, a nostalgia, o amor" temas exaustivamente tratados em Mornas eram as Noites, ou seja, Salústio é incisiva em suas escolhas, em cada palavra que decide escrever.

Não se pretende aqui comentar sobre cada obra citada acima, mas apenas tentar mostrar alguns aspectos que são pontuais e relevantes para o desenrolar desta pesquisa. Tendo em vista que a análise e referência a todos os títulos mencionados denotaria um trabalho mais detalhado e extenso, com um tempo maior para o desenvolvimento desse estudo.

Salústio, em seu livro Mornas eram as Noites, "incorpora inúmeros aspectos da feminilidade em Cabo Verde, opondo-se a uma cultura patriarcal e androcêntrica, que não vê a mulher como parte ativa dela, mas submetida àqueles que são mais 'fortes'” (PAZ; SCARTON, 2018, p. 135). A autora foge a essa submissão sempre que resolve mostrar em seus escritos tudo o que para ela é errado, deixando claro que em momento algum ela se faz conivente com situações que lhe pareçam preconceituosas, sexistas, pois revelar em suas literaturas tais atitudes autoritárias e machistas é um meio de denunciá-las. 
Num conto em particular, Foram as dores que o mataram, do já citado livro, a autora narra exatamente essa submissão e agressividade sofrida por sua personagem. Em um outro conto, um personagem diz: “Às vezes a dor acalma a impotência” (SALÚSTIO, 2002, p. 24). Essa passagem expõe literariamente a indignação de Salústio a casos de violência aos quais não se tem o controle necessário para eliminá-la ou se quer, amenizá-la.

Conto a conto, a autora vai tecendo frases, falas, parágrafos com sentidos e sentimentos que revelam as restrições e obrigações vividas por essas mulheres. "E apanhava pancada por todos os motivos [...] sonhos guardados intactos, porque não vividos eram os muros onde agora se sentavam para olhar o horizonte, eternamente futuro" (SALÚSTIO, 2002, p. 28). Tal parágrafo evidencia o silenciar de muitas mulheres diante das agressões sofridas, dos projetos e sonhos sucumbidos pela humilhação constante que estas enfrentam sem meios de defesa frente a uma cultura machista e patriarcal.

Compreende-se que “[...] a produção literária em Cabo Verde traz à tona textos cujos temas revelam as experiências sociais das mulheres cabo-verdianas, que, em situações insalubres, são tomadas como representantes de inúmeras realidades com dilemas de violência" (BRITO; LIMA, 2015, p. 56). E fazendo uso da literatura de Salústio e de temas utilizados pela autora, este artigo visa trabalhar a questão da violência de gêneros enfrentada e literariamente retratada nas personagens criadas pela escritora.

E é de suma importância ressaltar que, de acordo com Tedeschi (2016, p. 154)

[...] os estudos de gênero nos últimos tempos têm dado às ciências humanas e sociais são inquestionáveis, pois, além de tirarem as mulheres da invisibilidade do passado, levantaram um conjunto de questões e reflexões metodológicas importantes. [...] as mulheres, sem dúvida, participaram/participam da produção histórica e literária, mas pela 'porta dos fundos', assim como em todos os setores da vida produtiva e ativa das sociedades.

Ou seja, a contribuição de Salústio vai além da literária quando esta resolve escrever, ser parte ativa na contação da história de suas conterrâneas, como que servindo de porta-voz a cada uma delas e denunciando os absurdos que enfrentam caladas ao longo de séculos de patriarcalismo escancarado, numa cultura de costumes atrasados.

É interessante observar como a autora aborda assuntos significativamente relevantes e temáticos, nos proporcionando a uma reflexão sobre o modo como as mulheres cabo-verdianas estão inseridas na sociedade e como o descaso social reflete no dia a dia delas.

Dina Salústio utiliza como mecanismo, que além de ser importante e até mesmo persuasivo, sua habilidade com as palavras para escrever histórias, que por sua vez, é uma 
tentativa de tentar desmascarar ou resgatar, por meio da ficção, a forma marginalizada, como muitas mulheres vivem. Isso pode ser visto nesse trecho: "Sentia-se cansada. Pensou em atirar a lata de água no chão, esparrar-se no líquido, encharcar-se, fazer-se lama com aqueles caminhos que durante anos e mais anos lhe comiam a sola dos pés, lhe queimavam as veias, lhe roubavam as forças" (SALÚSTIO, 2002, p. 05).

Com base nesse fragmento, nota-se a situação em que a figura feminina é submetida, isto é, a condições precárias de trabalho em que a mulher, que por sua vez, também é mãe, está sendo condicionada, tendo em vista seu próprio sustento e ao dos filhos. Logo, é possível afirmar que a desigualdade social é um fator que transcende as páginas da obra Mornas eram as Noites. Ademais, a narrativa proposta pela escritora Salústio traz muitos questionamentos, os quais impulsionam o leitor a se permitir refletir sobre algo que parece não existir mais, porém não por não ser uma questão recorrente, e sim por ser um impasse, predominantemente atual, que mesmo após tantas lutas por justiça e igualdade social, a mulher continua vivendo em um cenário desfavorável.

Desse modo, tal afirmativa constitui-se numa problemática que vai passando de geração em geração, embora as mulheres tenham tido participação na criação dos "[...] estados modernos africanos, [...] uma vez que lutaram ao lado de homens para a libertação do continente" (TELO, 2017, p. 08), logo, tornando-as tão merecedoras de respeito e de igualdade social quanto eles. Observa-se que na prática não é isso que ocorre, culminando em uma difícil realidade de muitas mulheres, pois apesar de elas terem lutado em prol da nação e dos seus próprios direitos, infelizmente, ainda são vítimas da opressão do patriarcalismo.

Nesse sentido, no conto 8, Foram as dores que o mataram, inicialmente, é relatada a estória de um casal, isso pode ser visto no seguinte trecho: "Não importa o dia. Nem importa mesmo o ano em que se conheceram. Aconteceu. E houve um momento em que se amaram. Talvez tenha havido muitos momentos em que se amaram” (SALÚSTIO, 2002, p. 17).

A partir da leitura desse fragmento, há uma quebra de expectativa do leitor, pois logo em seguida a narrativa ganha novos desfechos, o que posteriormente irá despertar sentimento de revolta e sensibilizar quem está tendo contato direto com a obra, haja vista que o casal de personagens trará um conflito atual e recorrente, todavia não apenas em Cabo Verde, mas em diferentes lugares do mundo. Vejamos: "Foram as dores do meu corpo que o condenaram. Foram o sangue pisado, o ventre moído em pus" (SALÚSTIO, 2002, p. 17). "A partir de então, já observamos a violência que esse corpo feminino sofria, passando, até mesmo, por 'usos e abusos', conforme visto no conto" (CORTÊS; SANTOS; SANTOS, 2018, p. 55). 
Outro aspecto pertinente é que cada conto presente no livro da escritora cabo-verdiana, traz uma reflexão diferente. Ou seja, são histórias que se diferenciam uma da outra, porém, todas têm algo em comum, que no caso seria, a marginalização feminina. O conto Forçadamente mulher, forçosamente mãe traz uma abordagem significativa de uma jovem adolescente despreparada para ser mãe, porém o que mais aflige a quem está tendo contato com essa história é justamente o modo como se deu sua gravidez, podendo ser fruto de uma violência sexual. Isso pode ser corroborado a seguir:

Paula perdeu o olhar meigo e livre de adolescente. Agora apenas um rostinho triste e resignado que de longe em longe se abre, quando gargalhadas de meninas como ela despertam o rosto de menina que ainda existe. [...] Queria que ela e todas elas se juntassem e calassem para sempre os latidos daqueles que perseguem manhosamente as nossas meninas na quietude das noites. Com o seu ódio. E que desfizessem com as suas mãos de mães abandonadas. E os afogassem impiedosamente nas lágrimas de todas as crianças traídas. E esfomeadas (SALÚSTIO, 2002, p. 35).

Desse modo, observa-se a triste realidade sofrida pelo personagem, vítima de um sistema que em vez de solucionar o impasse, sugere assim como foi citado anteriormente, que a vítima, no caso a mulher, se una uma às outras para solucionar o problema. Por conseguinte, tal atitude pode ser vista como uma medida tomada a partir do desespero de não ter outro meio a recorrer.

Entretanto, a idealização da mulher imposta pela atual conjuntura social, desde tempos remotos, configura-se como uma questão que precisa ser trabalhada e discutida constantemente. Partindo desse pressuposto, no conto Um ilegítimo desejo, menciona nitidamente o preconceito, por meio de diversas culturas, gêneros, classes sociais e idades, o quanto uma mulher, que por se diferenciar dos paradigmas exigidos, pode ser vítima de inúmeros tipos de violência, e o personagem retrata justamente essa situação, uma vez que isso custou sua própria vida. Isso se deve, devido a profissão da personagem Djina, que em grande parte da sociedade, é tida como imprópria, pois tal mulher tinha como ganho financeiro a prostituição. Observe a seguir:

Nha Djina tinha a sua esquina. Ali fizera amigos. Despedira-se de amores. Mais tarde ali contrabandeara o seu próprio corpo. Na altura era Djina, apenas Djina. E porque contrabandear e não simplesmente vender? O corpo era dela. Porque contrabandear? Vendia-se. E o alvará da legitimidade, deram-lho as suas necessidades (SALÚSTIO, 2002, p. 31).

É pertinente analisar a indagação que ocorre durante a narrativa, pois mostra um posicionamento contrário aos preconceitos estabelecidos socialmente. Assim como isso pode 
ser encarado como um pedido de ajuda, que tenta fazer com que o leitor pense um pouco mais sobre esse assunto.

\section{Conclusão}

A leitura de Mornas eram as Noites, além de trazer uma reflexão do contexto social em que muitas mulheres cabo-verdianas estão inseridas, faz também uso da literatura como uma ferramenta para protestar e se posicionar contra essa repressão, na qual a figura feminina sofre. E isso pode ser reafirmado no trecho: “[...] o discurso hegemônico do patriarcalismo não conseguiu abafar determinadas vozes, principalmente de algumas mulheres [...] à subordinação" (TEDESCHI, 2016, p. 155).

Nesse sentido, Dina Salústio fez uma abordagem muito interessante, no qual foi traçado um perfil diferente para cada mulher presente no livro, em que cada uma delas apresenta características próprias, todavia com alguns aspectos em comum, que seriam o fato de todas elas serem vítimas de violência, desigualdade social e de gênero, tudo isso por conta de uma sociedade que majoritariamente, continua com um pensamento patriarcal. Além disso, um ponto positivo que qualifica todas essas personalidades femininas, configura-se na persistência de continuarem lutando pelo seu próprio espaço, por seus direitos, pela compressão da sociedade e por serem mulheres fortes.

As mulheres de Dina Salústio são mães, são amigas, são adolescentes, mas são, acima de tudo, fortes, mesmo que ainda sejam vítimas de violência, de descaso e de incompreensão. As personagens contam uma história de Cabo Verde, falam da sociedade, dos sentimentos íntimos de mulheres, e nos fornecem um pedacinho de pertencimento frente ao pouco que podemos conhecer da sua insularidade e experiências (SALÚSTIO, 1998 apud PAZ; SCARTON, 2018, p. 144).

Logo, é quase impossível ter contato com a obra da escritora Dina Salústio e em nenhum momento não nos identificarmos com alguma história narrada, seja por meio dos noticiários ou algum caso próximo ou até mesmo isolado, uma vez que a autora aborda problemáticas sociais que fazem parte do nosso dia a dia. Diante disso, observa-se que a literatura pode se tornar um objeto de manifestação social e política, que vai além de contar histórias bonitas, para se tornar um mecanismo de luta a favor daqueles que são marginalizados pela sociedade.

\section{Referências}

BRAGA, J. P. Entre dois mundos: a loucura feminina em A louca de Serrano, de Dina Salústio. Scripta, Belo Horizonte, v. 18, n. 35, p. 87-104, 2014. Disponível em: 
http://periodicos.pucminas.br/index.php/scripta/article/view/P.2358-

3428.2014v18n35p87/pdf. Acesso em: 13 nov. 2019.

BRITO, G. M. de; LIMA, T. M. de A. Dina Salústio e a violência de gênero na literatura cabo-verdiana. Veredas: Revista da Associação Internacional de Lusitanistas, n. 24, p. 5569, 19 jun. 2017. Disponível em:

https://revistaveredas.org/index.php/ver/article/view/354/343. Acesso em: 11 nov. 2019.

CABO VERDE. In: WIKIPEDIA: the free encyclopedia. 2018. Disponível em: https://pt.wikipedia.org/wiki/Cabo_Verde. Acesso em: 21 out. 2020.

CABO verde. Portal São Francisco. [S. l.: s. n.], 2018. Disponível em: https://www.portalsaofrancisco.com.br/turismo/cabo-verde. Acesso em: 22 out. 2020.

CÔRTES, D. L. A.; SANTOS, I. B. dos; SANTOS, J. de C. N. A mulher cabo-verdiana na literatura: possíveis formas de representação. Interdisciplinar - Revista de Estudos em Língua e Literatura, [S. l.], v. 30, p. 49-62, set. 2018.

LARANJEIRA, P. De letra em riste: identidade, autonomia e outras questões nas literaturas de Angola, Cabo Verde, Moçambique e São Tomé e Príncipe. Porto: Afrontamento, 1992. $112 \mathrm{p}$.

PAIXÃO, M. Conheça as "mulheres danadas" de Rachel de Queiroz. 27 out. 2017. Brasil de Fato. Disponível em: https://www.brasildefato.com.br/2017/10/27/conheca-as-mulheresdanadas-de-rachel-de-queiroz/. Acesso em: 16 nov. 2019.

PAZ, D. A.; SCARTON, M. da S. A condição feminina em Mornas Eram As Noites, de Dina Salústio. Revista Prâksis, Novo Hamburgo, v. 2, p. 133-145, jul. 2018. Disponível em: https://periodicos.feevale.br/seer/index.php/revistapraksis/article/view/1657. Acesso em: 12 nov. 2019.

PENA, R. F. A. África. Mundo Educação. [S. l.: s. n.], 2012. Disponível em: https://mundoeducacao.uol.com.br/geografia/africa-2.htm. Acesso em: 23 out. 2020.

SALÚSTIO, D. Mornas eram as noites. 3. ed. Praia: Instituto da Biblioteca Nacional, 2002. $91 \mathrm{p}$.

TEDESCHI, L. A. Os desafios da escrita feminina na história das mulheres. Raído, Dourados, v. 10, n. 21, p. 153-164, jan/jun. 2016. Disponível em: http://ojs.ufgd.edu.br/index.php/Raido/article/view/5217. Acesso em: 16 nov. 2019.

TELO, F. C. A. O pensamento feminista africano e a Carta dos princípios feministas para as feministas africanas. In: MUNDO DE MULHERES FAZENDO GÊNERO 11, 13, 2018, Florianópolis. Anais [...]. Florianópolis: UFSC, 2017, p. 1-12. 